\title{
Fuzzy Logic Controller for Grid Connected Wind Energy Conversion System
}

\author{
G.Muni Reddy*1, T.Gowri Manohar ${ }^{2}$ \\ ${ }^{1}$ Research Scholar, Department of EEE, S.V University, Tirupati, Andhra Pradesh, India \\ ${ }^{2}$ Professor, Department of EEE, S.V University, Tirupati, Andhra Pradesh, India
}

\section{Article Info \\ Article history: \\ Received Jan 4, 2018 \\ Revised Jan 22, 2018 \\ Accepted Feb 10, 2018}

\section{Keyword:}

Fuzzy logic controller (FLC) Instantaneous reactive power theory (IRPT)

Static synchronous compensator (STATCOM)

Total harmonic distortion (THD)

Wind energy conversion system (WECS).

\begin{abstract}
The use of renewable power sources, like wind power, has been increased recently due to climatic changes caused by fossil fuels and fast depletion of fossil fuels. This has lead to the tremendous increase in the interconnection of wind turbines to power system grid. This interconnection on a large number in to grid causes problems such as power quality, maintaining system voltage, reactive power compensation, control of grid frequency and aspects of power system grid stability. In this proposed scheme, a fuzzy logic based controller is employed for a STATCOM to improve the power quality. The proposed control scheme supplies the required reactive power to the system and thus relieves the source, leading to Unity Power Factor (UPF) at the source and also it injects currents to reduce total harmonic distortion (THD) to satisfy IEC standard. For extracting the reference currents, an instantaneous reactive power theory based control algorithm is employed. To determine the effectiveness of the proposed fuzzy logic controller, a comparative analysis is also performed with a PI controller and the results have been presented.
\end{abstract}

Copyright (C) 2018 Institute of Advanced Engineering and Science. All rights reserved.

Corresponding Author:

G.Muni Reddy,

Department of EEE, S.V University, Tirupati, Andhra Pradesh, India

Email: munireddyg@gmail.com

\section{INTRODUCTION}

Concern for increasing price of energy, climatic changes because of fossil fuels, rapid decline of fossil fuel reserves and the need to decrease green house gas emissions, these factors lead to the rapid growth of the sustainable energy sector. Among all the sustainable power sources, wind energy sector has undergone enormous progress recently due to its clean and economical nature [1-2]. During the past few years, wind turbines (WT) installations for both standalone and grid connected has been increased to a great extent in the entire world. For example, in European Union (EU) 12,800 MW of wind turbines were installed during 2015, an increase of $6.3 \%$ when compared to 2014. Wind power installations alone contributed for $44.2 \%$ of total power installations in EU in 2015. Wind energy installations are present is more than 80 countries globally and 28 countries are having more than $1 \mathrm{GW}$ installation capacity [3-4].

The Power Quality (PQ) of the power system grid will be influenced on incorporating Wind Energy Conversion System (WECS) in to the power system grid. The WECS is most commonly equipped with Induction Generator (IG) for generating electric power. The use of IG has merits like: economical, robustness, compact size, brushless construction (in squirrel cage arrangement), almost maintenance free, not necessary to have DC source for magnetization and inbuilt protection for overloads and short circuit. On the other hand, an IG takes reactive current for producing the necessary magnetic flux and thus the source is forced to supply the reactive power for the IG [5].

During the last decade, the grid integration of wind turbines has been increasing tremendously, leading to change of role of WECS from a minor power source to major power source, like thermal power 
stations, in the grid. Utilities consider the wind energy as the risky source in the aspects of the PQ and the PQ is considered as the complex issue in the grid connected WECS. The PQ of the WECS must be assessed on the basis of international standards and guidelines and it was initiated by International Electrotechnical Commission (IEC) in 1995. IEC issued a draft IEC-61400-21 standard for certifying the PQ requirements for grid connected WTS in the year 1998. Later, IEC published the first edition of IEC-61400-21standard in the year 2001 and then the second edition in the year 2008. Recently, measurement of the sub grouped harmonics, interharmonics and higher frequency harmonics is treated in IEC 61000-4-7 [6, 7].

Induction generator based isolated wind energy generation system studies is available in literature. Authors in [8] have proposed series compensated PWM inverter with a battery for regulating PQ aspects like voltage and frequency. Dynamics and stability analysis and control of WECS using an IG have been reported in [9], [10]. Control schemes for voltage and frequency control of isolated WECS based on IG has been reported in [11] and [12]. The effects of penetration of wind power in to the power system grid are no longer negligible as more number of wind generators is being integrated in to the grid. The study of the effects of grid integration of wind energy is available in the literature. Authors in [13] have investigated the mitigation of voltage fluctuations caused by turbulence using STATCOM. In [14], a STATCOM has been utilized to mitigate the voltage fluctuations and to improve fault ride through capability of grid connected wind farm with fixed speed IG.

The control strategy employed here is the conventional vector control with the negative sequence voltage feed-forward control, where the conventional vector control shall take care of PCC voltage and DC link voltage of STATCOM and the other control effectively suppressed over current of STATCOM. In [15], a STATCOM is utilized to overcome the PQ problems like voltage fluctuations and harmonics, but here the authors did not provide many details about control strategy employed. In [16], a STATCOM with a Battery Energy Storage System (BESS) is employed to overcome the PQ problems with the integration of wind farm with abundant wind power to the existing grid in the Southern California Edison power system. The proposed STATCOM-BESS system prevents the power system from collapsing under critical contingencies and provides voltage support. The BESS contributed to minimize wind power variations and to control wind farm output with in a preset values. In [17], the STATCOM is employed with SPWM technique having decoupled control to compensate the reactive power of wind farm. The controller in this paper is based on partial linearization and the control parameters are modulation ratio $(\mathrm{M})$ and phase difference angle $(\delta)$ to obtain improved STATCOM dynamic response and flexible reactive power control.

However, to ensure linearization accuracy, which makes the control of dc voltage slower, leading to large dc capacitance to ensure dc voltage stiffness. In [18], a STATCOM-BESS has been proposed to address two problems: PQ and stability. Two control strategies have been proposed, one for the PQ improvement by reducing the voltage fluctuations and the other for improving the WT stability. In [19], STATCOM is employed to minimize voltage fluctuations at Point of Common Coupling (PCC) and voltage instability during grid faults. Two different control schemes have been proposed; first one is based on conventional PI control and the other is a nonlinear control scheme based on input-output feedback linearization (IOL). Both the controllers performed equally well in flicker mitigation and transient PCC voltage regulation but IOL is better in transient dc-link voltage regulation. However, achieving the required power quality norms and reactive power compensation of the grid connected WECS using Fuzzy Logic Controller (FLC) based STATCOM by employing IRPT for extracting the reference currents for grid synchronisation has received a very little research attention.

In this paper, WECS with induction generator, connected to the grid consisting of the nonlinear load is considered for detailed study of the associated PQ problems and reactive power compensation. The IRPT based control algorithm extracts reference currents for grid synchronisation. The reference currents are compared with the actual currents and the error is fed to the Bang-Bang Current Controller (BBCC), which generates the switching signals to the STATCOM. The proposed controller provides reactive power to nonlinear load and induction generator and thus maintains UPF at the source side and also reduces THD in the system to the prescribed limits. To determine the effectiveness of the proposed FLC, a comparative analysis is also performed with a PI controller.

\section{CONFIGURATION OF GRID CONNECTED WIND ENERGY CONVERSION SYSTEM}

The proposed grid connected WECS for power quality enhancement is shown in Figure 1. The system consists of wind turbine, non linear load and STATCOM, all connected to grid. The details of the proposed control scheme are shown in Figure 2. The proposed control scheme shall take grid voltages, source currents, load currents and DC link capacitor actual and reference values as inputs. The control scheme shall produce desired switching pulses for the STATCOM as the output, so as to switch the STATCOM to inject currents in order to obtain the desired power quality norms.

IJEEI, Vol. 6, No. 1, March 2018 : 37 - 44 


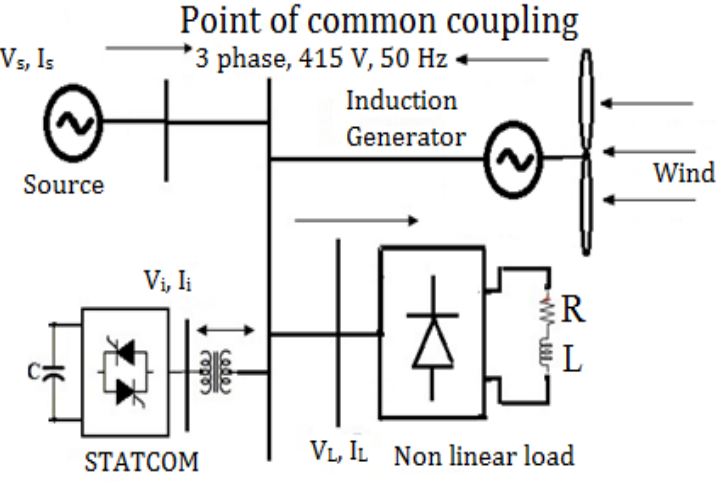

Figure 1. Grid connected wind turbine system

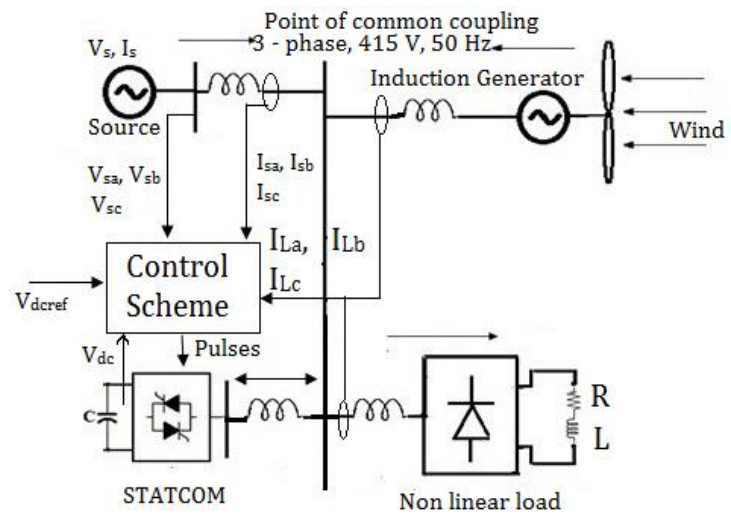

Figure 2. Control scheme details

\subsection{Wind Energy Conversion System (WECS)}

The Wind turbine is coupled to generator so as to convert the kinetic energy of the wind to rotating torque for the generator. Normally 3- $\Phi$ alternators, PMSG and IGs are used as generators in WECS. PMSG and squirrel cage IG are popular because of reliability and economy. In the proposed grid connected system, the WT used is constant speed with pitch control. The squirrel cage induction generator is used in the proposed system because of economical, simple and rugged construction, no need of DC excitation, and has natural protection for short circuit [20]. The total power available in the wind is

$$
P_{w}=\frac{1}{2} \rho A v_{w}^{3}
$$

Where A is area swept by WT blade in $\mathrm{m}^{2}, \rho$ is air density in $\mathrm{kg} / \mathrm{m}^{3}, v_{w}$ is the wind speed in $\mathrm{m} / \mathrm{s}$. WT extracts a portion of power in wind, as given by

$$
P_{m}=C_{P} P_{w}
$$

Where $\mathrm{C}_{\mathrm{p}}$ is the power coefficient of WT. The electrical power output is then [21]

$$
P_{e}=c_{p} \eta_{m} \eta_{g} P_{w}
$$

Where $\eta_{m}$ is the mechanical system efficiency and $\eta_{g}$ is the efficiency of the generator.

\subsection{Static Synchronous Compensator (STATCOM)}

In recent times, a Voltage Source Inverter (VSI) based advanced static var compensators, also known as STATCOM, is utilized for reactive power control [22]. The STATCOM is also a VSI, but connected to a grid system rather than to a passive load. The magnitude and phase angle of the STATCOM are controlled to achieve the desired reactive power control. Depending on the voltage magnitude of STATCOM, it behaves like an inductor or capacitor. If voltage value is higher than the grid voltage, it behaves as a capacitor, for a less voltage than grid, it behaves like an inductor. Therefore by continuous voltage variation, the reactive power output of STATCOM shall be varied continuously [22, 23].

\section{CONTROL SCHEME}

\subsection{Extraction of Reference Currents using IRPT for Grid Synchronization}

Instantaneous Reactive Power Theory (IRPT) is used for extracting reference currents for grid synchronisation. The details of this control strategy are shown in Figure 3. The 3- $\Phi$ voltages at PCC $v_{s a}, v_{s b}$ and $v_{S c}$ and load currents $\mathrm{i}_{\mathrm{La}}, \mathrm{i}_{\mathrm{Lb}}$, and $\mathrm{i}_{\mathrm{Lc}}$ are sensed to determine the instantaneous active and reactive powers $[24,25,26]$.

The sensed PCC voltages and load currents are transformed in to $\alpha-\beta$ coordinate system with the help of Clark's transformation. 


$$
\left(\begin{array}{l}
v_{\alpha} \\
v_{\beta}
\end{array}\right)=\sqrt{\frac{2}{3}}\left(\begin{array}{ccc}
1 & -\frac{1}{2} & -\frac{1}{2} \\
0 & \frac{\sqrt{3}}{2} & -\frac{\sqrt{3}}{2}
\end{array}\right)\left(\begin{array}{l}
v_{s a} \\
v_{s b} \\
v_{s c}
\end{array}\right) \text { and }\left(\begin{array}{l}
i_{\mathrm{L} \alpha} \\
i_{\mathrm{L} \beta}
\end{array}\right)=\sqrt{\frac{2}{3}}\left(\begin{array}{ccc}
1 & -\frac{1}{2} & -\frac{1}{2} \\
0 & \frac{\sqrt{3}}{2} & -\frac{\sqrt{3}}{2}
\end{array}\right)\left(\begin{array}{l}
i_{\mathrm{L} a} \\
i_{\mathrm{L} b} \\
i_{\mathrm{L} c}
\end{array}\right)
$$

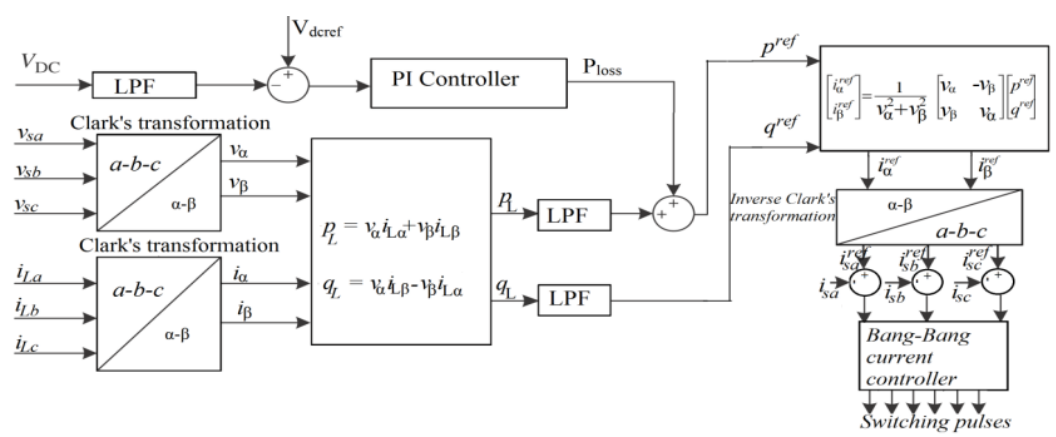

Figure 3. Block diagram of control scheme for reference current extraction

The instantaneous active and reactive powers $\left(p_{L}, q_{L}\right)$ can be calculated as

$$
\left(\begin{array}{l}
p_{\mathrm{L}} \\
q_{\mathrm{L}}
\end{array}\right)=\left(\begin{array}{cc}
v_{\alpha} & v_{\beta} \\
-v_{\beta} & v_{\alpha}
\end{array}\right)\left(\begin{array}{l}
i_{\mathrm{L} \alpha} \\
i_{\mathrm{L} \beta}
\end{array}\right)
$$

The above powers shall have both DC and AC components

$$
p_{L}=\bar{p}_{L^{+}} \stackrel{\square}{p}_{L} \text { and } q_{L}=\bar{q}_{L}+\stackrel{\square}{q}_{L}
$$

Two LPFs are employed to extract DC components $\left(\bar{p}_{L}, \bar{q}_{L}\right)$ only. To obtain self supporting DC bus, the losses of the STATCOM must be supplied by the source. The output of the PI controller gives $\mathrm{P}_{\text {loss }}$, as shown in equation 7:

$$
P_{\text {loss }}(n)=P_{\text {loss }}(n-1)+K_{p d}\left\{v_{d e}(n)-v_{d e}(n-1)\right\}+K_{i d} v_{d e}(n)
$$

Where $v_{d e}(n)=v_{d c r f}(n)-v_{d c}(n)$ is the error between reference and actual DC link capacitor voltage at $\mathrm{n}^{\text {th }}$ sampling instant and $K_{p d}$ and $K_{i d}$ are the proportional and integral gain constants of the PI controller. The obtained reference currents shall be in $\alpha-\beta$ coordinate system and by applying inverse Clark's transformation, the obtained $\alpha-\beta$ coordinate system reference currents are transformed to abc frame.

$$
\left(\begin{array}{l}
i_{s a}^{r e f} \\
i_{s b}^{r e f} \\
i_{s c}^{r e f}
\end{array}\right)=\sqrt{\frac{2}{3}}\left(\begin{array}{cc}
1 & 0 \\
-\frac{1}{2} & \frac{\sqrt{3}}{2} \\
-\frac{1}{2} & -\frac{\sqrt{3}}{2}
\end{array}\right)\left(\begin{array}{cc}
v_{\alpha} & v_{\beta} \\
-v_{\beta} & v_{\alpha}
\end{array}\right)^{-1}\left(\begin{array}{l}
p^{r e f} \\
q^{r e f}
\end{array}\right)
$$

\subsection{Bang-Bang Current Controller (BBCC)}

In the $\mathrm{BBCC}$, hysteresis comparator controls the steady-state error by varying the hysteresis bandwidth (HB).In this paper, a two level hysteresis comparator namely, lower hysteresis band (LHB) and upper hysteresis band (UHB) is employed to determine the steady-state error. The actual currents are measured by sensors and the reference currents are calculated using Eq. (8). On comparing actual and 
reference currents, a current error is obtained, which is fed to a BBCC. The BBCC shall generate switching signals for IGBTs of STATCOM [27, 28]. Figure 4 shows the method for obtaining switching signals.

\subsection{Fuzzy Logic Controller (FLC)}

Recently, a lot of interest has been shown in the research of applications of FLC. FLC is an expert system, which tries to implement human knowledge in the form of if-then rules. In the conventional control systems, like PI and PID controllers, rigorous mathematics is needed to model the system and if the mathematical model is not known, then the conventional controllers cannot be designed. The structure of FLC consists of four parts, namely, Fuzzification, knowledge base, inference and defuzzification [29, 30, 31].

In this paper, the PI controller is now replaced with a FLC, as shown in Figure 5. The inputs to the FLC are error and change in error and the output of the FLC is $\mathrm{P}_{\text {loss. }}$. The two inputs variables and one output variable are fuzzified by using the seven fuzzy sets: NL (negative large), NME (negative medium), NS (negative small), Z (zero), PS (positive small), PME (positive medium), and PL (positive large). The normalized membership functions for input and output variables are shown in Figure 6. The knowledge is represented in the form of rules as indicated in Table 1. Inference is done using Mamdani's min operator and finally, the output is converted to crisp set by defuzzification using centroid method.

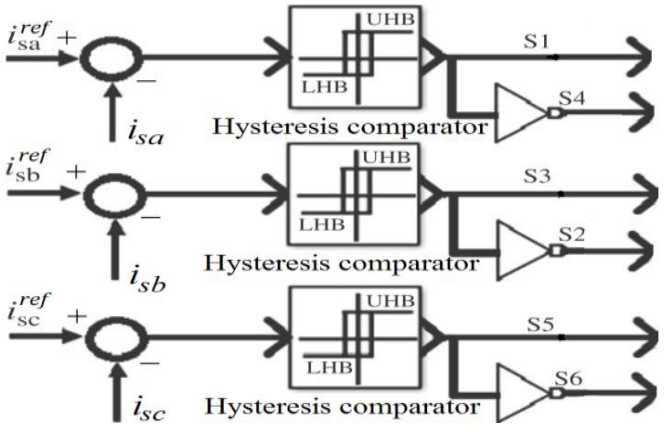

Figure 4. Bang-Bang Current Controller

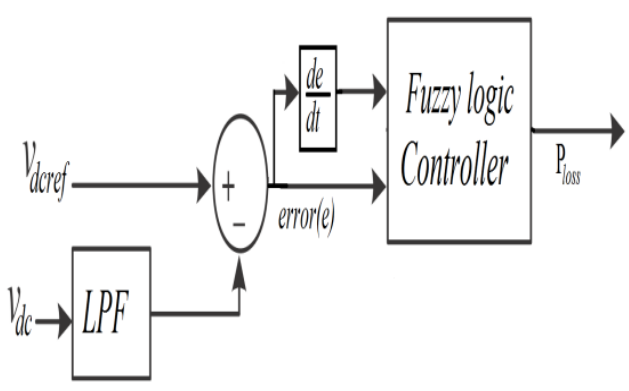

Figure 5. Block diagram of FLC

\section{RESULTS AND ANALYSIS}

The system considered for power quality improvement, as shown in Figure 1, is simulated using MATLAB/SIMULINK. The power quality of the system is mainly affected by the nonlinear load and wind turbine. In this paper, to have the comparative analysis of the performance of the proposed FLC based STATCOM with IRPT based control scheme, the proposed system is also simulated without STATCOM and then with PI controller STATCOM.

\subsection{System performance without STATCOM and its controller}

Due to nonlinear load, the load current is not sinusoidal, as it is clear from Figure 7(a) and this load current cause the source current distortions, as shown in Figure 7(b). The THD of the source current is 26.12 $\%$, as shown in Figure 8 and it is highly undesirable. Both nonlinear RL load and induction generator consume reactive power causing power factor at the source lagging, as it is clear from Figure 9.

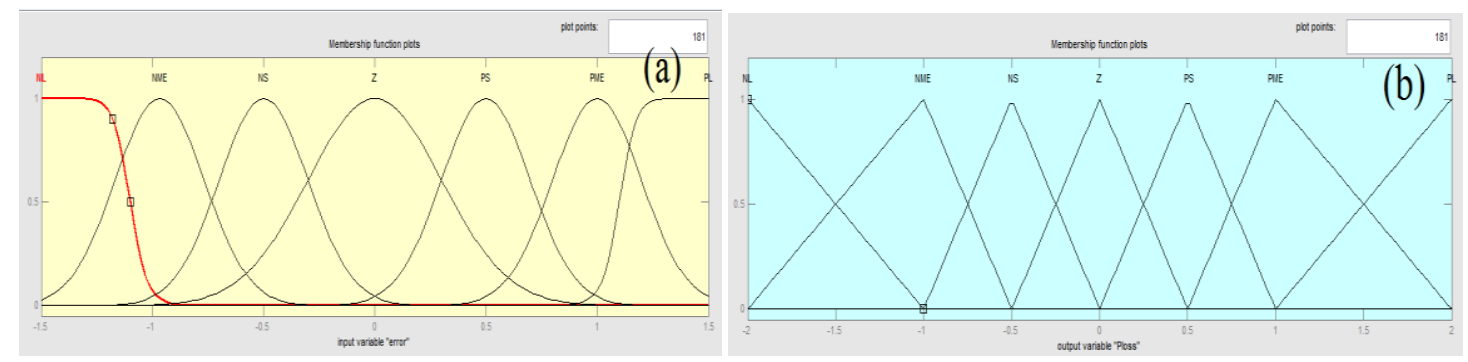

Figure 6. Membership functions (a) error and change in error (b) output, $\mathrm{P}_{\text {loss }}$ 
Table 1. Rule Base

\begin{tabular}{|c|c|c|c|c|c|c|c|}
\hline \multirow{2}{*}{$\begin{array}{c}\text { Change in } \\
\text { error }\end{array}$} & \multicolumn{5}{|c|}{ Error } & \multirow[b]{2}{*}{ PME } & \multirow[b]{2}{*}{ PL } \\
\hline & NL & NME & NS & $\mathrm{Z}$ & PS & & \\
\hline $\mathrm{NL}$ & $\mathrm{NL}$ & $\mathrm{NL}$ & $\mathrm{NL}$ & $\mathrm{NL}$ & NME & NS & $\bar{Z}$ \\
\hline NME & NL & NL & NL & NME & NS & Z & PS \\
\hline $\mathrm{Z}$ & NL & NME & NS & $\mathrm{Z}$ & PS & PME & PL \\
\hline PS & NME & NS & Z & PS & PME & PL & PL \\
\hline PME & NS & $\mathrm{Z}$ & PS & PME & PL & PL & PL \\
\hline
\end{tabular}

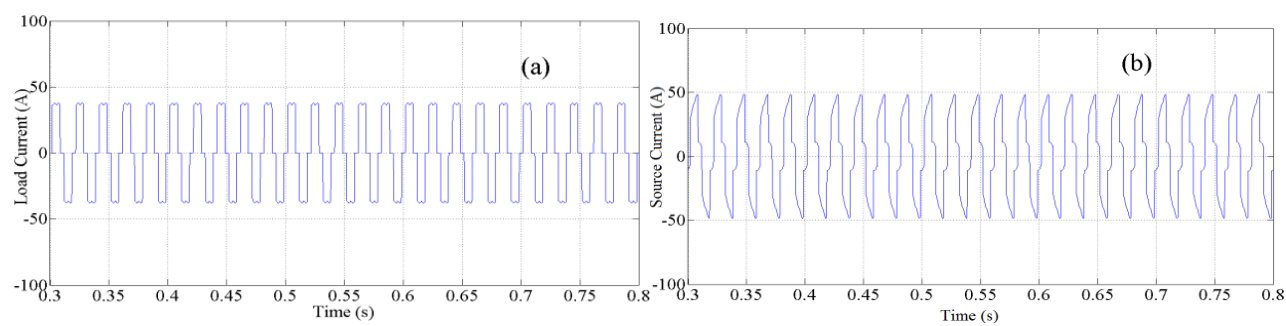

Figure 7. (a) Load Current (b) Source Current, Without STATCOM

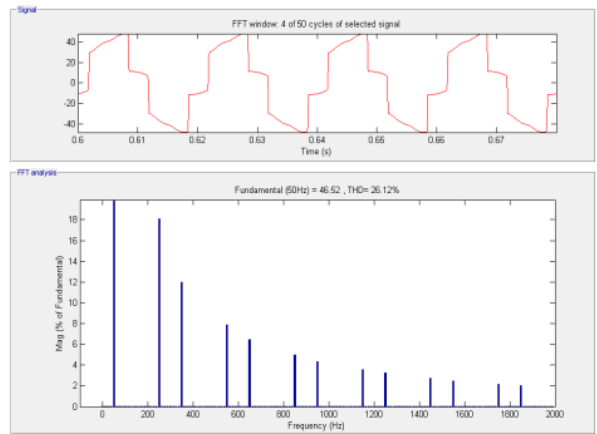

Figure 8. FFT analysis of Source current

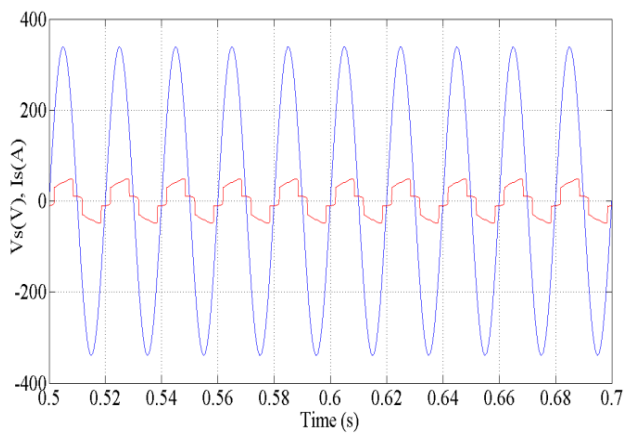

Figure 9. Supply voltage \& supply current

\subsection{System performance with STATCOM and its IRPT based controller with PI controller}

The same system is simulated with the STATCOM and its IRPT based controller with PI controller. Due to non-linear load, the load current is highly distorted, as shown in Figure 7(a). Because of this load, harmonics are injected to source current also, but the STATCOM injected current shall cancel out the harmonics, thus causing the source current to be sinusoidal with a THD of $4 \%$ as shown in Figure 10. Figure 11 shows the waveform of source voltage and source current and from this waveform it can be seen that that the UPF is maintained.

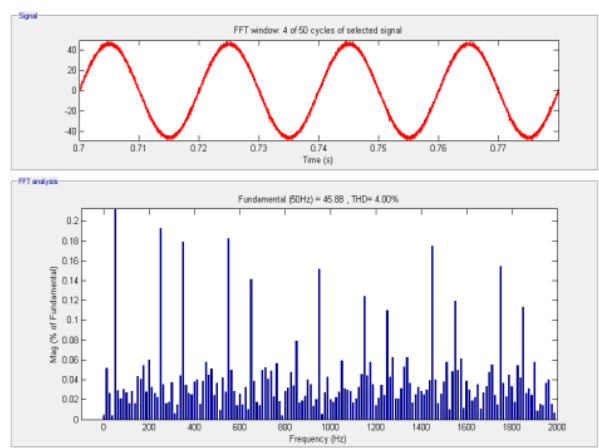

Figure 10. FFT analysis of Source current

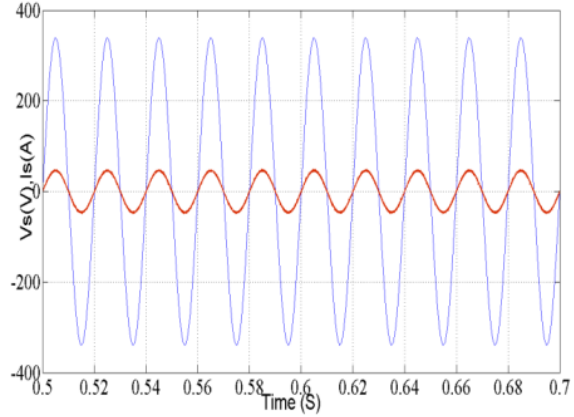

Figure 11. Supply voltage \& supply current

IJEEI, Vol. 6, No. 1, March 2018 : $37-44$ 


\subsection{System performance with STATCOM and its IRPT based controller with FLC}

The same system is simulated with the STATCOM and its IRPT based controller with FLC. Because of non-linear load, harmonics are injected to source current also, but the STATCOM injected current shall cancel out the harmonics, thus causing the source current to be sinusoidal with a THD of $3.39 \%$ as shown in Figure 12. Figure 13 shows the waveform of source voltage and source current and it can be seen that that the UPF is maintained. Figure 14 shows the response of DC link voltage with both the controllers and it can be seen that the response is better with FLC.

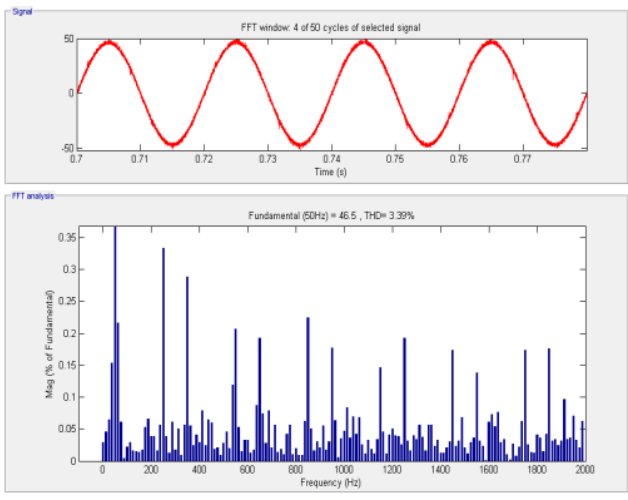

Figure 12. FFT analysis of Source current

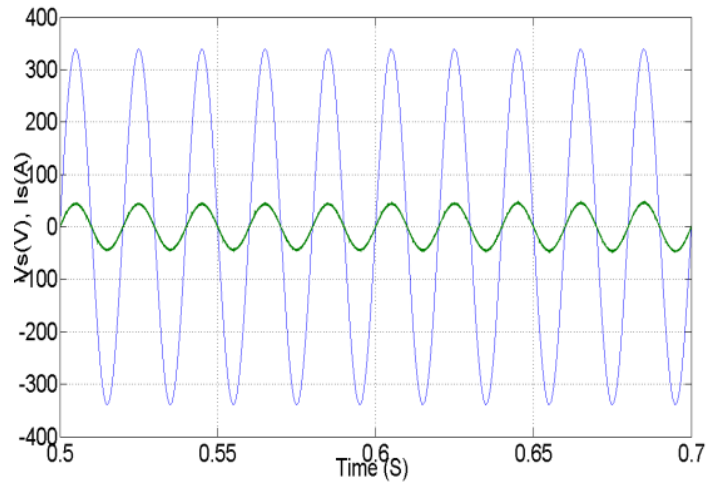

Figure 13. Supply voltage \& supply current

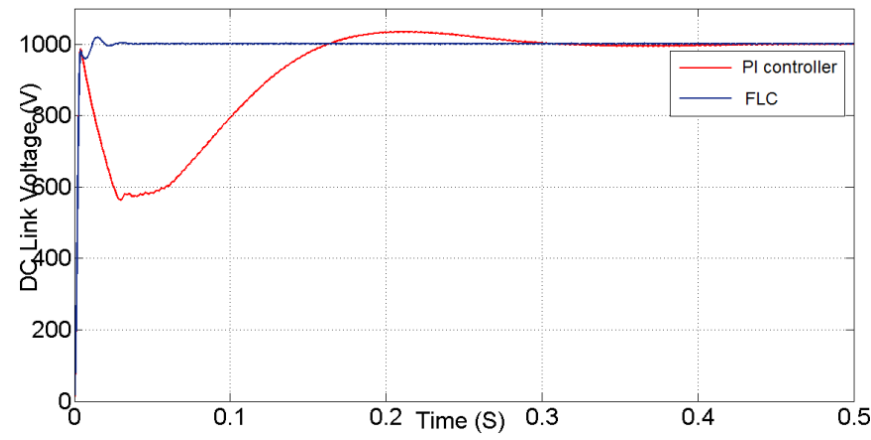

Figure 14. Response of DC link voltage with PI controller and FLC

\section{CONCLUSION}

The power quality improvement of grid connected WECS using fuzzy logic controller based STATCOM with IRPT based control scheme has been presented in this paper. The test system has nonlinear RL load and WECS integrated with induction generator, which causes the potential power quality problems. The proposed controller shall inject currents in to the grid and reduces the source current THD from $26.12 \%$ to $3.39 \%$. The controller shall also supply the required reactive power for the load and induction generator and thus helps to maintain UPF at the source. The IRPT based STATCOM with FLC has superior performance when compared to IRPT based STATCOM with PI controller as THD values are $3.39 \%$ and 4 $\%$ respectively. The grid connected WECS with IRPT based STATCOM with FLC has shown the outstanding performance by satisfying the power quality norms as per the IEC standard.

\section{REFERENCES}

[1] $20 \%$ Wind Energy by 2030. (July, 2008). Available at http://www.osti.gov/bridge switching.

[2] Wind Energy Benefits. (April, 2011). Available at $h t t p: / / w w w . e e r e . e n e r g y . g o v / w i n d / p d f s / 49053 . p d f$

[3] Wind in power 2015 European statistics. Available at http://www.ewea.org/fileadmin/files/library /publications /statistics/EWEA-Annual-Statistics-2015.pdf

[4] Global Wind Energy Outlook - 2016. Available at http://www.apren.pt/fotos/newsletter/conteudos/ globalwindenergyoutlook2016_1483545282.pdf

[5] R.C. Bansal, T.S. Bhatti, and D.P. Kothari. On some of the design aspects of wind energy conversion systems. 
Energy Conversion and Management. 2002; 43(16): 2175-2187.

[6] J. M. Carrasco et al. Power-Electronic Systems for the Grid Integration of Renewable Energy Sources: A Survey. IEEE Trans. on Industrial Electronics. 2006; 53(4): 1002-1016.

[7] J.J. Gutierrez, J. Ruiz, P. Saiz, I. Azcarate, L.A. Leturiondo and A. Lazkano (2011). Power quality in Grid-Connected wind turbines. Dr. Ibrahim Al-Bahadly (Ed.), InTech, DOI: 10.5772/15175.

[8] E. Mulzadi and T. Lipo. Series compensated PWM inverter with battery supply applied to an isolated induction generator. IEEE Trans. Ind. Applications. 1994; 30(4):1073-1082.

[9] L. M. Fernandez, J. R. Saenz, and F. Jurado. Dynamic models of wind farms with fixed speed wind turbines. Renewable Energy. 2006; 31(8): 1203-1230.

[10] J. L. Munda and H. Miyagi. Stability analysis and control of a wind turbine driven induction generator. Electrical Power Components and Systems. 2002; 30(12): 1223-1233.

[11] A. A. Shaltout and M. A. Abdel-Halim. Solid state control of wind driven self-excited induction generator. Electric Machines \& Power Systems. 1995; 23(5): 571-582.

[12] J. FAIZ. Design and implementation of a solid state controller for regulation of output voltage of a wind driven self-excited three phase squirrel cage induction generator. Proc. IEEE $8^{\text {th }}$ International Conference on Electrical Machines and Systems. Nanjing, China. 2005; 3: 2384-2388.

[13] R.Fadaeinedjad, G.Moschopoulos and M. Moallem. Using STATCOM to mitigate voltage fluctuations due to aerodynamic aspects of wind turbines. Proc. 2008 IEEE Power Electronics Specialists Conference. Rhodes, Greece. 2008; 3648-3654.

[14] Guizhen Tian, Shengtie Wang and Guangchen Liu. Power quality and Transient Stability Improvement of Wind Farm with Fixed-Speed Induction Generators Using a STATCOM. Proc. of 2010 IEEE International Conference on Power System Technology. Hangzhou. 2010; 1-6.

[15] V.Suresh Kumar, Ahmed F.Zobaa, R.Dinesh Kannan, and K.Kalaiselvi. Power quality and Stability Improvement in Wind Park System Using STATCOM. Jordan Journal of Mechanical and Industrial Engineering. 2010; 4(1): 169 176.

[16] J. Castaneda, J. Enslin, D. Elizondo, N. Abed and S. Teleke. Application of STATCOM with energy storage for wind farm integration. IEEE PES T\&D. New Orleans, LA, USA. 2010; 1-6.

[17] H.T.Wu, Y. H. Liu. Novel STATCOM Control Strategy for Wind Farm Reactive Power Compensation. IEEE AsiaPacific power and Energy Engineering conference. Wuhan. 2011; 1-5.

[18] A. Arulampalam, M. Barnes, N. Jenkins and J.B. Ekanayake. Power quality and stability improvement of a wind farm using STATCOM supported with hybrid battery energy storage. IEE Proc.-Gener. Trans. Distribution. 2006; 153(6): 701-710.

[19] Wei Qiao and Ronald G. Harley. Power quality and Dynamic Performance Improvement of Wind Farms Using a STATCOM. IEEE Power Elect. Specialists Conference. Orlando. 2007; 1832-1838.

[20] Prashanth NA and P Sujatha. Commonly used Wind Generator Systems: A Comparison Note. Indonesian Journal of Electrical Engineering and Computer Science. 2017; 7(2): 299-311.

[21] Dr. R. C. Bansal, Dr. Ahmed F. Zobaa, Dr. R. K. Saket. Some Issues Related to Power Generation Using Wind Energy Conversion Systems: An Overview. International Journal of Emerging Electric Power Systems. 2005; 3(2): article 1070.

[22] N.G.Hingorani and L.Gyugi, understanding FACTS: concepts and technology of flexible AC transmission systems, IEEE, New York, 2000, ch. 5.

[23] S. Deepa, S. Praba, V. Deepalakshmi, L. Jayaprakash, M. Manimurugan. A Fuzzy GA based STATCOM for power quality improvement. International Journal of Power Electronics and Drive System (IJPEDS). 2017; 8(1): 483-491.

[24]B. Singh and J. Solanki. A Comparison of Control Algorithms for DSTATCOM. IEEE Transactions on Industrial Electronics. 2009; 56(7): 2738-2745.

[25] M. I. M. Montero, E. R. Cadaval and F. B. Gonzalez. Comparison of Control Strategies for Shunt Active Power Filters in Three-Phase Four-Wire Systems. IEEE Transactions on Power Electronics. 2007; 22(1): 229-236.

[26] Bhim Singh, Ambrish Chandra, and Kamal Al-Haddad. Power Quality Problems and Mitigation Techniques. First edition. United Kingdom: John Wiley and Sons Ltd. 2015. 119-121.

[27] Saman Hosseini Hemati, Ashkan Mohammadi. Power Control of High Penetration PV in Distribution Network. TELKOMNIKA Indonesian Journal of Electrical Engineering. 2015; 15(2): 217-228.

[28] Ahmad Albanna. Modeling \& Simulation of Hysteresis Current Controlled Inverters Using MATLAB, Applications of MATLAB in Science and Engineering”, Prof. Tadeusz Michalowski (Ed.), ISBN: 978-953-307-708-6, InTech.

[29] X. X. Yin, Y. G. Lin, W. Li, H. W. Liu and Y. J. Gu. Fuzzy-Logic Sliding-Mode Control Strategy for Extracting Maximum Wind Power. IEEE Transactions on Energy Conversion, 2015; 30(4): 1267-1278.

[30] Xiu-xing Yin, Yong-gang Lin, Wei Li, Ya-jing Gu, Hong-wei Liu, Peng-fei Lei. A novel fuzzy integral sliding mode current control strategy for maximizing wind power extraction and eliminating voltage harmonics. Energy, 2015; 85(1): 677-686.

[31] Xiu-xing Yin, Yong-gang Lin, Wei Li, Ya-jing Gu, Peng-fei Lei, Hong-wei Liu. Sliding mode voltage control strategy for capturing maximum wind energy based on fuzzy logic control. International Journal of Electrical Power \& Energy Systems, 2015; 70: 45-51. 